\title{
RECYCLING OF WASTE LUBRICANTS BY USING LOW-TONNAGE TECHNOLOGY
}

\author{
Irina Belinskaia, Alexander Kartoshkin \\ Saint-Petersburg State Agrarian University, Russia \\ belinska@yandex.ru
}

\begin{abstract}
In recent years human activities have influenced a significant increase in the amount of waste lubricants (WL). Annually the minimum number of waste lubricating materials in Russia amounts to 500 thousand tons, out of it only 14-15\% are reprocessed, the rest is illegally dumped into the soil or waterways. Environmentally hazardous components of waste lubricants are polychlorinated biphenyls, derived from the sulfur - and chlorine-containing additives, some biocides, organic metal compounds (lead, barium, antimony, zinc), nitrites. They are distributed in atmosphere, water, soils, appearing in food, are getting into the food chain of men and the result is a shift of the ecological balance. A way to solve the problem of recycling of waste lubricants is to develop low-tonnage technologies of recycling using multifunctional modular regenerative complex. Its development is based on use of transportable small-sized plants with a capacity from 50 to $3001 \cdot \mathrm{h}^{-1}$; mobile plants with a capacity from 250 to $1500 \mathrm{l} \cdot \mathrm{h}^{-1}$; stationary small-sized plants with a capacity from 300 to $3000 \mathrm{l} \cdot \mathrm{h}^{-1}$. The implementation of recycling of waste lubricants by using of the low-tonnage technology allows to reduce emissions of WL in the environment and hence improve its ecology indicators, formulate mechanisms of economic incentives aimed at encouraging the development of systems for collection and disposal of WL, introduce modern technologies for processing of WL for the rational use of energy resources.
\end{abstract}

Keywords: lubricating oil, re-use, low-tonnage technologies.

\section{Introduction}

In recent years human activities have influenced a significant increase in the amount of waste lubricants (WL). Annually the minimum number of waste lubricating materials in Russia amounts to 500 thousand tons, out of it only 14-15\% are reprocessed [1], the rest is illegally dumped into the soil or waterways [2] . Environmentally hazardous components of waste lubricants are polychlorinated biphenyls, derived from the sulfur - and chlorine-containing additives, some biocides, organic metal compounds (lead, barium, antimony, zinc), nitrites. They are distributed in atmosphere, water, soils, appearing in food, are getting into human food chain and the result is a shift of the ecological balance [3].

In this regard, the problem of disposal and recycling of waste lubricants acts as nationwide. Establishment of an effective regeneration system will significantly reduce negative environmental impacts and increase the economic efficiency of agricultural enterprises in the country. Providing them with the opportunity to sell WL will affect the reduction of emissions, and using them as a secondary resource will reduce the production costs. The results of recycling materials can be used for maintenance of individual components and assemblies, act as the basic material for the temporary (1.5-3 years) and long-term (5-7 years) preservation of the transmission units, can be applied for the intended purpose.

\section{Materials and methods}

The problem of disposal of spent lubricating oils is successfully solved in many countries, the priority is the restoration of their original properties by regeneration. In order to promote the process of recycling of WL enterprises-processors in the majority of the EU countries state subsidies are allocated, a technological infrastructure is created.

Methods of regeneration of waste lubricants are different; each has its advantages and disadvantages, the characteristics of the used devices and installations.

The most active currently the following methods of regeneration are used:

- physico-chemical methods of extraction of waste oil-containing components heat treated at low temperatures (separation, dehydration, separation, adsorption);

- chemical and thermo-chemical methods (thermal cracking, catalytic hydrogenation, vacuum distillation, chemical treatment with decomposition);

- thermal conversion;

- neutralization using biological and microbiological methods. 
The choice of the method of disposal and regeneration of WL is associated with the peculiarities of the separate businesses and their needs in the products of processing, the specifics of the state management system, financial opportunities etc. At present, in our country the physico-chemical methods of regeneration are most widely used.

System recycling and disposal of WL in agricultural production given the large territorial extent of our country seems feasible to implement using low-tonnage technologies of disposal of spent lubricants, which are the used physico-chemical methods of processing of spent lubricating oil.

Consolidated system organization of recycling of WL is shown in the figure.

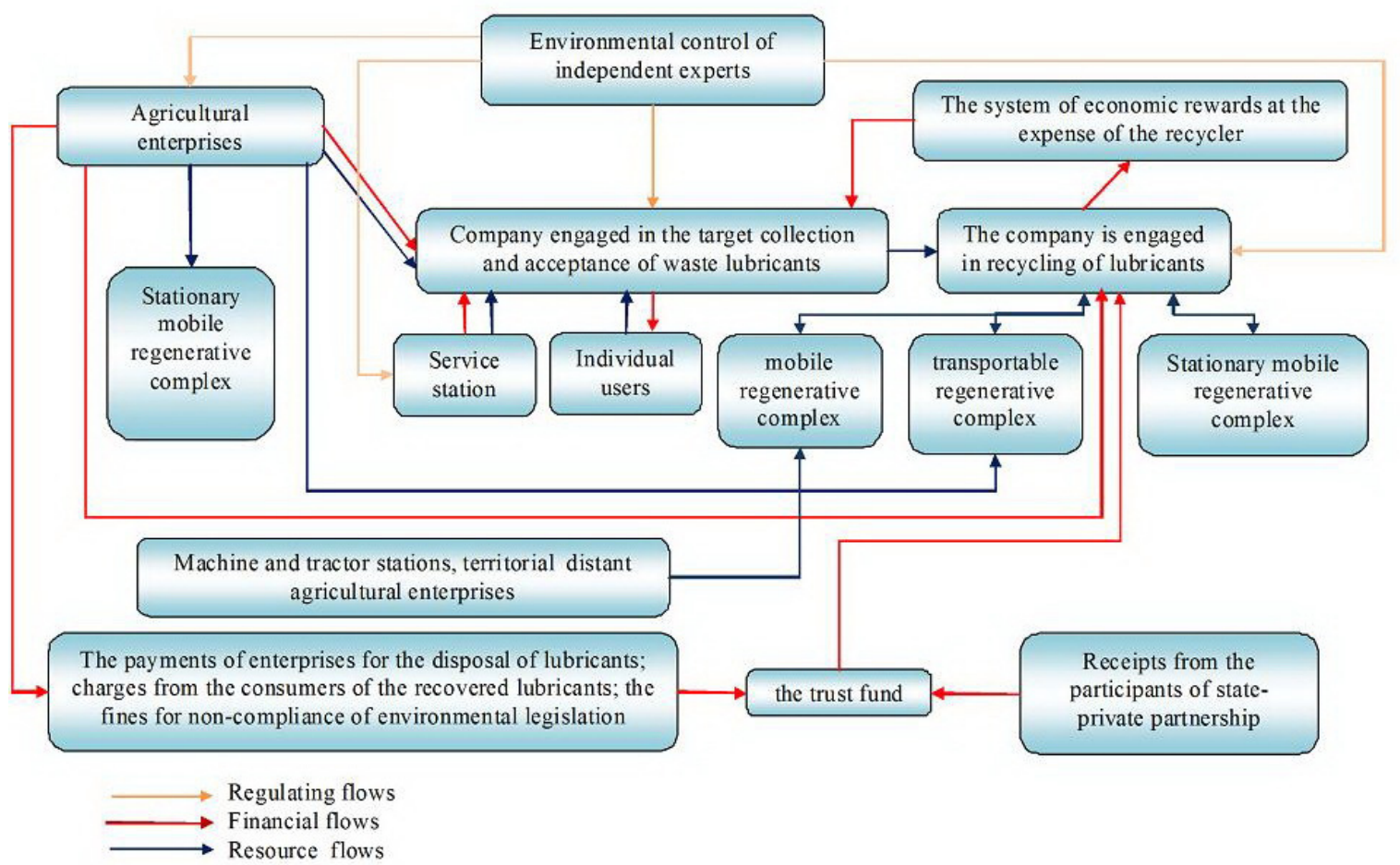

\section{Fig. 1. System organization of recycling waste lubricants}

The basis of the implementation of the concept is regulating the activities of the state, as expressed in the creation of conditions for an independent assessment of the level of ecological safety of territories and creation of mechanisms of economic incentives of all participants in the system. It is necessary to develop normative-legal base of support of the enterprises-processors and implementation of economic incentives for the introduction of small-sized regenerative systems in the agricultural sector. Financial support finds its expression in the functioning of a specialized trust fund that is the source for the introduction of the regenerative technology. Modification of small-size regenerative complexes can be used in a variety of organizational forms, based on the size of the expected economic effect. Large agricultural enterprises, which are at a considerable distance from the technical infrastructure, have the opportunity to purchase a specialized transportable regeneration complex and use it themselves. The regeneration results of spent lubricating oils, which are not useful for further use, are forwarded to the companies that collect WL. The most important step in establishing an effective regeneration system of WL is organization of separate, selective collection, which prevents mixing of WL with other types of waste lubricants, which allows saving essential for later use physico-chemical properties. For it agricultural enterprises should use the storage container for different types of WL provided by specialized companies. The cost of purchasing these containers is included in the sales price of the spent lubricant after the accumulation of a certain amount.

Technological implementation of the concept is determined by the type of organizational decisions and used for modification of the small-size regeneration of the complex:

1. The creation of its own divisions on the regeneration of WL on the agricultural enterprise. Depending on the scale of the agricultural enterprise and the volume of the used lubricant material the recycling process can be implemented on a stationary post or in the transportable mobile 
regenerative complex, which works in the departments located at a considerable territorial remoteness from the main production building.

2. The addition in the functions of the machine and tractor stations (MTS) serving remote agricultural enterprises, the option of collection, disposal and subsequent regeneration of used lubricants by using the mobile regenerative complex.

In this case, MTS can provide the following services to:

- make the collection of waste oils;

- perform the storage of waste oils for the purpose of their stockpiling until optimal amounts;

- produce primary purification of WL "on the spot";

- do full cleaning of waste lubricants and their regeneration.

3. Organization of independent legal entity which collects of WL, their subsequent disposal and recycling. Given the scale of production of the recovered lubricant, density of population, size of investments, the performance of these functions may be entrusted to a single company or distributed among several specialized companies specializing separately on collection and reception of waste lubricants, recycling and subsequent sale of products derived from the WL. For it stationary and mobile types of small-size regenerative complex can be used that collect WL on the whole territory bounded by the criterion of minimum transport costs.

Every modification of the regenerative small-size complex has its own specific characteristics. Mobile units have on board a full-sized regeneration complex and the laboratory for analysis of oils with a choice of recovery technologies according to it. Performance of the mobile unit is 250-1500 $1 \cdot \mathrm{h}^{-1}$. The basic equipment of the stationary units consists of a fixed module, cleaning module and transportable module with the system of automatic technology selection, regeneration, depending on the condition of the feedstock. Performance of the transportable regeneration plant is from 50 to $300 \mathrm{l} \cdot \mathrm{h}^{-1}$. Its feature of compact mobile installation is the availability of a replacement unit that allows implementing the necessary technology of regeneration of a particular type of WL based on the results of the input control of the physical and chemical parameters. The total capacity of the mobile installation is less than $0.75 \mathrm{~m}^{3}$, the production capacity from 50 to $300 \mathrm{l} \cdot \mathrm{h}^{-1}$. This type of installations is economically beneficial for consumers having the same type of WL. This module can be quickly disassembled, shipped to recycling a large batch of WL, and then returned, assembled and incorporated in the work.

The choice of modifications of the small-size regenerative complex depends on the peculiarities of agricultural enterprises and the value of the expected economic effect.

For agricultural enterprises and enterprises specializing in the processing of WL, the decision to implement the project to create regenerative complexes is based on the comparison of the capital costs and the size of the anticipated income and it involves the calculation of net present value (NPV):

$$
N P V=\sum_{t=1}^{T} \frac{R}{(1+r)^{t}}-\sum_{t=1}^{T} \frac{C I}{(1+r)^{t}},
$$

where $R$ - revenue - expected cash flow, monetary unit;

$C I$ - capital investments for construction of the object of regenerative waste lubricants, monetary unit;

$t \ldots T$ - implementation period of the project, years;

$(1+r)^{t}-$ discount factor that takes into account the change in the value of cash investments during the period of implementation of the project, \%;

$r$ - discount rate [4].

The regeneration process for processing of WL can be implemented on a production basis (in stationary regeneration complex), by leasing of the transportable module and mobile recycle complex in frame of partnership with the machine-tractor stations.

The expected cash flows from the project are calculated according to the formula:

$$
R=R_{r p}-C_{l}-C_{o v},
$$


where $R_{r p}$ - revenue from sales of products derived from WL, monetary unit;

$C_{l}$ - logistics costs for taking into account the transportation costs for delivery and acquisition costs of waste lubricants, monetary unit;

$C_{o v}$ - overhead costs of the enterprise, including direct (cost of utilities, salaries, purchase of used materials, etc.) and indirect costs (marketing and administrative costs, taxes, etc.), monetary unit.

The revenue from sales of recovered products:

$$
R_{r p}=V_{\text {un.r.l. }} \cdot Q_{r l}
$$

where $V_{\text {un.r. } . \text { }}-$ unit value realization of the recovered lubricants, monetary unit $^{-1}$;

$Q_{r l}$ - quantity of the recovered lubricants, 1 .

Logistics costs are calculated:

$$
C_{l}=C_{t}+\left(V_{a s} \cdot Q_{a s}\right),
$$

where $C_{t}-$ transportation costs for delivery of waste oils and returning the regenerated materials, monetary unit;

$V_{u . a s}$ - unit cost of acquisition waste lubricants, monetary unit;

$Q_{a s}$ - quantity of acquisition waste lubricants, 1 .

Costs that form in the future sale the value of the recovered lubricant depend on the state of the raw material (degree of contamination of the WL, that is determined by the physico-chemical indicators) and the operational parameters of the products of regeneration.

Transportation costs are calculated according to the formula:

$$
C_{t}=S \cdot C_{u . f .},
$$

where $S$ - distance from agricultural enterprises to specialized enterprises (mileage of vehicle), $\mathrm{km}$;

$C_{u . f .}-$ unit cost of fuel, monetary unit $\mathrm{km}^{-1}$.

The regeneration company should be placed in such a way that the total transportation costs of agricultural enterprises for the delivery of waste oils are minimal, $C_{t} \rightarrow \min$.

In the case of calculation of the logistics costs when using a mobile regeneration complex it is necessary to calculate the operational transport costs $\left(C_{o . t .}\right)$ :

$$
C_{\text {o.t. }}=C_{m}+C_{d}+C_{t y r}+C_{p . e .},
$$

where $C_{m}-$ cost of maintenance, monetary unit;

$C_{d}$ - depreciation of vehicle, monetary unit;

$C_{t v r}$ - cost of purchase of tires, monetary unit;

$C_{p . e}-$ cost of power electricity, monetary unit.

The regulations allow creating a mathematical model to determine the boundaries of appropriate use of small-size complexes regeneration of the spent lubricating oils.

$$
\begin{gathered}
N P V=\sum_{t=1}^{T} \frac{R}{(1+r)^{t}}-\sum_{t=1}^{T} \frac{C I}{(1+r)^{t}} \rightarrow \max \\
R=R_{r p}-C_{l}-C_{o v} \\
R_{r p}=V_{\text {un.r.l. }} \cdot Q_{r l} \\
C_{l}=\left\{\begin{array}{c}
C_{t}+\left(Q_{r l} \cdot V_{\text {un.r.l. }}\right) \mid K_{C l}=0 ; \\
C_{t}+\left(Q_{r l} \cdot V_{\text {un.r.l. }}\right)+C_{\text {o.t. }} \mid K_{C l}=1 ; \\
C_{t}=S \cdot C_{\text {u.f. }}
\end{array}\right.
\end{gathered}
$$




$$
\begin{gathered}
C_{\text {o.t. }}=C_{m}+C_{d}+C_{t y r}+C_{p . e .} \\
S \geq 0 ; 0 \leq Q_{r . l .} \leq Q_{\max } ; 0<K_{C l}<1 ; K_{C l}<Z
\end{gathered}
$$

Capital investments $(C I)$ to create a recycle plant are treated as conditionally constant. Maximum sales volume in the restored lubricating oil $\left(Q_{r l}\right)$ is determined by the capacity of regeneration of complex and the time of its work in the year. The coefficient $K_{C l}$ denotes the type of the regeneration complex: if using the transportable module, $K_{C l}$ is 0 , if using the mobile regeneration complex, $K_{C l}$ is indicated by 1 .

\section{Results and discussion}

On the basis of studies, a concept was developed for the use of low-tonnage technologies of recycling of waste oils, the elements (participants) of the system were determined, their functions and the conditions of existence. The choice of modifications of the compact regenerative system depends on the peculiarities of agricultural enterprises and the expected cash flows. As a result of the calculations it was established that the use of stationary recovery units is suitable for consumers of WL, which are at the distance to the regeneration company no more than $20 \mathrm{~km}$, - in this case, the company-recycler makes recycling at the manufacturing facilities or uses the transportable regeneration module. Mobile regeneration complex can be used for maintenance of agricultural enterprises, the coverage radius of not more than $100 \mathrm{~km}$. The feasibility of using the stationary regeneration complex for an agricultural enterprise is defined on the basis of the net present value.

\section{Conclusions}

Thus, the introduction of the concept of recycling and processing of WL based on the use of multifunctional small-sized regenerative complexes allows to:

- reduce the emissions of WL into the environment from agricultural enterprises;

- establish a system of secondary use of resources and decrease the production costs on agricultural enterprises;

- identify ways of using small-tonnage technologies in the regeneration system of WL.

\section{References}

1. Makolova L. V. Environmental prerequisites necessary recovery and re-use of waste automotive oils. Terra Economics, Vol. 1, 2011. pp. 60-63.

2. Belinskaia I.V., Kartoshkin A.P., Ovchinnikova E.I. Ecological aspects of Russia agricultural engineering education. Proceedings of International conference on education 2012, July 30August 3, Turku, Finland, 2012, p.85.

3. Kartoshkin A.P., Mangiev S.P. Environmental hazards of dumping of waste lubricating oils. Proceedings of International conference "Engines - 2007", M.: MGTU. 2007. pp. 424-428.

4. Rimer M. I., Kasatov A. D., Matienko N. N. Economic evaluation of investment. SaintPetersburg. Peter. 2008. 480 p. 